\title{
Advanced care planning
}

\section{A patient-centered approach to end-of-life care}

\author{
Konstantinos Alexopoulos (Meds 2016) \\ Faculty Reviewer: Dr Ravi Taneja, MD, FRCPC (Departments of Anesthesiology and Critical Care)
}

\section{INTRODUCTION}

The scenario is all too familiar to the critical care physician working in a major teaching centre, or perhaps, even a peripheral intensive care unit (ICU) with limited capacity: an elderly patient is admitted to the emergency department status post-acute stroke. The patient has developed a high systolic blood pressure, a widened pulse pressure and abnormal respirations, which all point to increased intracranial pressure and a potential risk for brain stem herniation. A plan is made to admit the patient to the ICU for definitive management, which includes endotracheal intubation, ventilatory support, a hypnotic infusion and an osmotic diuretic like mannitol. ${ }^{1}$ The following morning, the patient's family arrives and there are medical decisions to be agreed upon and executed through a family meeting. Up until this point in this patient's life, there has been no formal discussion between family members around the topic of end-of-life care. ${ }^{2}$ No substitute decision maker (SDM) has been appointed. This culminates in family members vehemently disagreeing on what their loved one would have wanted. The critical care specialist physician is in a moral quandary. Like most things in medicine, effective advanced care planning is a prerequisite for success. However, there are always barriers to overcome in the process of planning, especially when it comes to death and dying.

Advance care planning (ACP) results in an advanced directive that expresses one's future preferences for medical decisions when one might be incapable of making such decisions. ${ }^{3}$ The goal of ACP is to improve patient-centred care and potentially reduce the intensification of care at the end of life. ${ }^{4}$ The ACP process is a topdown modus operandi. The big picture involves making the transition from living to dying as painless as possible from every facet: medical, physical, emotional, spiritual and religious. Unfortunately, these psychosocial needs tend to be forgotten in the early stages of managing a patient in critical condition. From a medical perspective, the ICU was developed in the mid-20th century to facilitate invasive monitoring and medical intervention to those critically ill or injured patients. Critical care medicine burgeoned into a mecca of technological and life-saving advancements. ${ }^{5}$ As a direct consequence of the development of the ICU, some physicians have proposed that Western society has overmedicalized the experience of death and dying. Rather than dying at home surrounded by friends and family, the elderly have been wasting away and dying in a sterile hospital setting. ${ }^{6}$ The idea of extending life without consideration for quality of life has been a topic of contention in the management and allocation of ICU-specific resources. Canadian physicians are having to come up against the harsh reality that these resources are limited. Being cognizant of this, physicians need to overcome their inherent paternalistic instinct to keep a patient alive using invasive monitoring, vasopressors and mechanical ventilation. Failure to identify the point where medical intervention can unintentionally prolong patient suffering is a disservice to the patients and their families.

\section{DISCUSSION}

Patients who are terminally ill consistently identify their top priorities as avoiding suffering, being with family and not becoming a burden to others, but SDMs often do not realize this. ${ }^{2}$ An example to illustrate this would be a patient with heart failure and underlying arrhythmia that resulted in the placement of an internal defibrillator/pacemaker. The patient's condition has deteriorated and the patient is admitted to hospital for medical management. Over the last few days of the patient's life, the family watches their loved one progress through the stages of dying. Intermittently, the defibrillator fires, causing discomfort to patient and family alike. Despite this, the patient's husband as her SDM refuses to deactivate the defibrillator because he does not want to be responsible for killing her. Herein arises the issue of education surrounding endof-life care and decision making facilitated by an open dialogue between all parties involved.

$\mathrm{ACP}$ at its core is meant to be a process that facilitates communication and engages the participant in ongoing reflection. ${ }^{4}$ Ideally, ACP involves members of the healthcare team, family members and loved ones. A large barrier to the process is the unwillingness of some patients to engage in these discussions, because they are forced to face the gravity of their illness and prognosis. Conversely, physicians often avoid the topic because their paternalistic instinct hopes to shield the patients from the harsh reality of their mortality. While there is a certain degree of emotional upset that is bound to occur, most patients when offered a chance to discuss their wishes have found such conversations empowering. ${ }^{78}$ In modern medical practice, a patient-centred approach is emphasized and valued highly. However, it may be inappropriate to initiate ACP discussions at the onset of terminal illness. In doing so, we may be indeed asking the patient to predict the individual course of his or her disease process. This violates a core tenet of patient-centred care: that pathology is not experienced on a universal level by all. Rather, illness is defined as a unique experience within a biopsychosocial model that includes not only scientific fact, but humanistic factors like emotional and cultural differences.

Recent research at the Schlegel Institute for Aging at the University of Waterloo has provided some valuable insight to assist in guiding the patient experience in preparing for death and dying. 
Less than half of those Canadians interviewed had discussed their preferences for end-of-life care with someone. An overwhelming majority believe that these discussions should be had with a family member. Most striking is that most Canadians believed they should think about or at least discuss end-of-life care while they are in good health. ${ }^{9}$ The barrier between patient and physician seems to be a problem of initiating the discussion in a manner which causes the least amount of stress for the patient. ${ }^{10}$ Yet, the physician requires an appropriate and a comprehensive strategy to be able to approach these discussions. There is no effective check-list approach to ACP. There exist some forms of checklist to facilitate discussion. However, death is shared universal event that is experienced very differently amongst individuals and their families. ${ }^{8}$ Successful ACP is reliant on a shared approach of open and honest communication between physician and patient. ${ }^{11}$

Critical care physicians often engage in family meetings and are perceived to have some degree of competence in eliciting patients' wishes and facilitating decisions during the end-of-life period. The checklist approach to family meetings is one that does not consider individual patient experiences or prior knowledge of their disease and medical interventions like invasive monitoring and mechanical ventilation. Research by Scheunemann et al examined transcripts of 71 recorded family meetings. The findings suggest that a patient's values and preferences are explored poorly in discussion with surrogates. Patient preferences were not discussed at all in $30 \%$ of family meetings. Values like independence, known to be highly important to patients, was not discussed in $88 \%$ of those meetings. Yet, clinicians made explicit recommendations in $61 \%$ of conferences. The study has obvious limitations, so the results cannot be extrapolated to all patients and every ICU setting. ${ }^{11,12}$ The study was performed in two ICU settings in California. The authors purport that they observed younger physicians who specialize in internal medicine or neurology. The Hawthorne effect can also not be excluded. These physicians knew they were being observed for the purpose of study. Thus, the variety in physician behaviour and approach was not fully captured in this study. What can be inferred is the fact that physicians may not always be considering their patients' wishes and values. ${ }^{12}$

\section{CONCLUSION}

The shared care model of ACP, between patient and physician is something that needs to be examined further and expanded upon. Clinicians may not have elicited patients' wishes because of time constraints or a fear of upsetting the patient. Patients may be fearful to initiate the conversation and are simply waiting for a trigger to come along. In the context of patient-centred care, patients present with an issue and it is the responsibility of the clinician to assess and manage the complaint. If healthy patients were regularly prompted to think about end-of-life care in cooperation with their health care provider, it is likely that we would be better able to preserve some dignity in death by avoiding costly and unnecessary hospitalization.

\section{REFERENCES}

1. Meena AK, Suvarna A, and Kaul S. Critical care management of acute stroke. Neurol India. 2002 Dec;50(1):S37-49.

2. Whittington FJ. Denying and defying death: the culture of dying in 21st century America. Gerontologist. 2011;51(4):571-9.

3. Prendergast TJ. Advanced care planning: pitfalls, progress, promise. Crit Care Med. 2001;29(2):N34-9.

4. Heyland DK, Barwich D, Pichora D, Dodek P, Lamontagne F, You JJ, Tayler C, Porterfield P, Sinuff T, Simon J. Failure to engage hospitalized elderly patients and their families in advance care planning. JAMA Intern Med. 2013 Apr;173(9):778-87.

5. Luce JM. End of life decision making in the intensive care unit. Am J Respir Crit Care Med. 2010 Feb;182:6-11.

6. Heyland DK, Lavery JV, Tranmer JE, Shortt SE, Taylor SJ. Dying in Canada: is it an institutionalized, technologically supported experience? J Palliat Care. 2000;16:S10-6.

7. Barnes K, Jones L, Tookman A, King M. Acceptability of an advance care planning interview schedule: a focus group study. Palliat Med. 2007;21:23-8.

8. Mullick A, Martin J, Sallnow L. An introduction to advance care planning in practice. BMJ. 2013. 347: f6064

9. Stolee P, Zaza C, Sharatt MT. Later life care planning for older adults and families. J Appl Geront. 2014;33(6):710-36.

10. Simon J, Porterfield P, Bouchal SR, Heyland D. Not yet and just ask: barriers and facilitators to advance care planning - a qualitative descriptive study of seriously ill, older patients and their families. BMJ Support Palliat Care. 2015 Mar;5(1):54-62.

11. Manara A. Bespoke End-of-life decision making in ICU: has the tailor got the right measurements? Crit Care Med. 2015;43(4):909-10.

12. Scheunemann LP, Cunningham TV, Arnold RM, Buddadhumaruk P, White DB. How clinicians discuss critically ill patients' preferences and values with surrogates: an empirical analysis. Crit Care Med. 2015;43(4):757-64. 